\title{
USO DE FERRAMENTAS DE AVALIAÇÃO INSTITUCIONAL PELA GESTÃO ESCOLAR PARA AFERIR A QUALIDADE SOCIAL DA ESCOLA: UMA REVISÃO DE LITERATURA DAS PESQUISAS DA BDTD (2010-2014)

\author{
Rosane Fátima Vasques ${ }^{1}$ \\ Oto João Petry ${ }^{2}$
}

\section{RESUMO}

Esta pesquisa tem como foco verificar quais ferramentas de avaliação institucional são comumente utilizadas pela gestão escolar, na educação básica, para avaliar a qualidade social de uma instituição escolar, bem como demonstrar quais caminhos a gestão escolar e a avaliação institucional têm percorrido nos trabalhos científicos brasileiros nos últimos anos. Para tanto, realizou-se uma revisão de literatura, tendo como fonte de dados a Biblioteca Digital Brasileira de Teses e Dissertações (BDTD). Constatou-se a escassez de ferramentas de avaliação institucional que possam auxiliar o gestor escolar em seu trabalho diário. Ao mesmo tempo, confirmou-se que é indispensável à gestão escolar fazer uso da avaliação institucional para melhorar a qualidade educacional. Os estudos sinalizam a Avaliação Institucional Participativa como um bom caminho para a gestão escolar diagnosticar e repensar sua instituição. Por fim, salientamos que nenhuma ferramenta conseguirá apreender a realidade escolar (em sim mesma), mas pode auxiliar a gestão escolar na busca pela qualidade social da instituição.

Palavras-chave: Gestão Escolar. Avaliação Institucional. Qualidade Social.

\begin{abstract}
This research focuses on investigating which institutional assessment tools are commonly used by school management in basic education to assess the social quality of an educational institution, as well as demonstrating what paths school management and institutional assessment have traced in the Brazilian scientific studies in the last years. To this end, we carried out a literature review, having as data source the Brazilian Digital Library of Theses and Dissertations. A lack of institutional assessment tools that can assist school management in their daily work was found. At the same time, it was confirmed that it is essential to school

\footnotetext{
${ }^{1}$ Mestre em Educação. Docente do departamento de Ciências Humanas - Universidade Regional Integrada do Alto Uruguai e das Missões (URI), Campus Erechim.

2 Doutor em Educação. Coordenador e docente do curso de Pós-graduação Stricto Sensu em Educação Universidade Federal da Fronteira Sul (UFFS), Campus Chapecó.
} 
management to make use of institutional assessment to improve educational quality. Studies indicate Participatory Institutional Assessment as a good way for school management to diagnose and rethink its institution. Finally, we emphasize that no tools will be able to capture the reality of a school (in itself), but can help school management in the pursuit of the institution's social quality.

Keywords: School Management. Institutional Assessment. Social Quality.

\section{Introdução}

Primando pela importância de se aliar a avaliação institucional a gestão da escola, o objetivo deste trabalho ${ }^{3}$ é, por meio uma revisão de literatura, verificar quais ferramentas de avaliação institucional são comumente utilizadas na educação básica, no campo da gestão escolar, para avaliar a qualidade de uma instituição, bem como demonstrar quais caminhos a gestão escolar e a avaliação institucional têm percorrido nos trabalhos científicos brasileiros nos últimos anos. Para tanto utilizou-se como fonte de dados, da Biblioteca Digital Brasileira de Teses e Dissertações (BDTD). Assim, no decorrer da pesquisa dá-se destaque às principais tendências analíticas que constituem os estudos sobre gestão escolar e avaliação institucional.

Desse modo, antes da revisão proposta, em um primeiro momento buscou-se definir o conceito de qualidade escolar que acreditamos ser o ideal para se pensar a escola brasileira. Em um segundo momento, procurou-se evidenciar qual deve ser a função primordial da avaliação institucional em uma instituição escolar. E num terceiro momento primou-se por destacar a importância de se aliar essa esfera de avaliação à gestão escolar, para facilitar e auxiliar o trabalho do gestor escolar, buscando melhorar a qualidade escolar.

\section{Educação de qualidade social}

Se o que se pretende com uma avaliação institucional é definir o que vem a ser uma escola de qualidade, primeiro reafirma-se que nos distanciamos de uma proposta de qualidade total (economicista, empresarial, pragmática) inserida em uma esfera gerencialista e performática. Opondo-se a isso, adotou-se a qualidade social como sendo a ideal para garantir o direito à educação e a função social da escola. Então, o que vem a ser a qualidade social?

Para Libâneo (2008), qualidade social é aquela que promove o domínio de

\footnotetext{
${ }^{3}$ Este trabalho trata-se de um recorte de uma pesquisa mais ampla realizada pela autora, sob orientação do coautor, em seu trabalho de conclusão do curso de Pós-Graduação em Educação, Stricto Sensu, pela UFFS Campus Chapecó.
} 
conhecimento e o desenvolvimento das capacidades necessárias ao atendimento das necessidades individuais e sociais dos sujeitos, à inserção no mundo do trabalho e à constituição da cidadania, com vistas a uma sociedade mais justa e igualitária. Em resumo, “escola com qualidade social significa a inter-relação entre qualidade formal e política, é aquela baseada no conhecimento e na ampliação de capacidades cognitivas, operativas e sociais, com alto grau de inclusão" (LIBÂNEO, 2008, p. 66).

\begin{abstract}
O sociólogo Pedro Demo analisa o conceito de qualidade e chega a algumas conclusões. A qualidade é, genuinamente, um atributo humano, e o que representa melhor a marca humana é o desenvolvimento humano. Dessa forma, "qualidade essencial seria aquela que expressa a competência ou a massa de manobra". Competência histórica significa capacidade de agir, de intervir na realidade, portanto, capacidade participativa. Nesse sentido, a educação é o melhor caminho para desenvolver a competência histórica de fazer-se sujeito. Em síntese, buscar qualidade em qualquer instituição significa trabalhar com seres humanos para ajudá-los a se construírem como sujeitos. (LIBÂNEO, 2008, p. 66)
\end{abstract}

Então, conforme Libâneo (2008), Demo distingue, no campo da educação, a qualidade formal da qualidade política. A qualidade formal é o conhecimento que o sujeito aprende na escola, a formação básica capaz de torná-lo apto a saber pensar para melhor intervir. Já a qualidade política são os fins e valores sociais do conhecimento, ou seja, o objetivo de intervir na realidade visando ao bem comum. Desse modo, a qualidade formal e a qualidade política tornam-se complementares e indissociáveis na perspectiva de uma educação com qualidade social.

Nesse sentido, Libâneo (2008) caracteriza uma educação escolar de qualidade social nos seguintes aspectos: sólida formação básica capaz de desenvolver habilidades cognitivas, operativas e sociais por meio de conteúdos escolares, propiciar a preparação para o mundo tecnológico e comunicacional, e integrar a cultura provida pela ciência, técnica, linguagem, estética e ética; formação para a cidadania possibilitando preparar os sujeitos para participarem de organizações e movimentos populares; elevação do nível escolar para todos; integração entre a cultura escolar e outras culturas, rumo a uma educação intercultural e comunitária; formação de qualidades morais, traços de caráter, atitude, convicções, com base em ideais humanistas; condições físicas, materiais e financeiras de funcionamento, condição de trabalho, remuneração digna e formação continuada do profissional docente; incorporação das novas tecnologias de informação e comunicação no cotidiano escolar. (LIBÂNEO, 2008)

Percebe-se que essas características definidoras de uma escola de qualidade social vêm ao encontro de garantir o direito de educação a todos e a função social da escola, sintetizada, conforme Paro (2007), na formação do cidadão em dupla dimensão: individual e 
social. A dimensão individual é o provimento do saber necessário ao desenvolvimento do educando, "dando-lhe condições de realizar o bem-estar pessoal e o usufruto dos bem sociais e culturais postos ao alcance dos cidadãos" (PARO, 2007, p. 16). A dimensão social referese à formação do cidadão tendo em vista sua contribuição para a sociedade, sintetizada na educação para a democracia.

Nesse sentido, uma escola de qualidade social, como argumenta Silva (2009, p. 225), "é aquela que atenta para um conjunto de elementos e dimensões socioeconômicas e culturais que circundam o modo de viver e as expectativas das famílias e de estudantes em relação à educação". É uma escola que busca "compreender as políticas governamentais, os projetos sociais e ambientais em seu sentido político, voltados para o bem comum; que luta por financiamento adequado, pelo reconhecimento social e valorização dos trabalhadores em

educação" (SILVA, 2009, p. 225). É, portanto, uma escola que se preocupa com o conhecimento e com vivências efetivamente democráticas.

Então, uma avaliação institucional que prime por estes aspectos poderá auxiliar o gesto escolar em suas atividades, o que salientamos na seção que segue.

\section{Avaliação institucional X gestão escolar}

A gestão escolar está situada na abrangência dos estabelecimentos de ensino, sendo tarefas específicas dessas instituições a gestão de seu pessoal, de seus recursos materiais e de seus recursos financeiros. Dessa forma, cabe à escola a gestão de todo o seu patrimônio imaterial (pessoas, ideias, cultura) e material (parte física da instituição). "Além dessas atribuições, e acima de qualquer outra dimensão, está a incumbência de zelar pelo que constitui a própria razão de ser da escola - o ensino e a aprendizagem” (VIEIRA, 2007, p. $62)$.

A LDB (lei n 9.394/96) foi a primeira legislação a dedicar atenção particular a essa esfera e a atribuir incumbências às instituições de ensino. Tais incumbências, conforme o art. 12, são: elaborar e executar sua proposta pedagógica; administrar seu pessoal e seus recursos materiais e financeiros; assegurar o cumprimento dos dias letivos e horas-aula estabelecidas; velar pelo cumprimento do plano de trabalho de cada docente; prover meios para a recuperação dos alunos de menor rendimento; articular-se com as famílias e a comunidade, criando processos de integração da sociedade com a escola; informar os pais e responsáveis sobre a frequência e o rendimento dos alunos, bem como sobre a execução de sua proposta pedagógica. 
Já a avaliação institucional, como argumenta Freitas et al. (2009, p. 35), "é um processo que envolve todos os seus atores, com vistas a negociar patamares adequados de aprimoramento, a partir de problemas concretos vivenciados por ela". Para melhorar a qualidade da educação prestada, uma instituição deve focar seus esforços em construir uma avaliação do todo da instituição que possa, de um lado, fazer uso dos resultados das avaliações de larga escala e, de outro, refletir sobre o resultado apontado pela sua avaliação institucional para fortalecer a avaliação da aprendizagem. Diferentemente da avaliação de larga escala, externa à escola, e da avaliação da aprendizagem, em nível de sala de aula, a avaliação institucional é interna à escola e se realiza sob seu comando. Nesse sentido, esse nível de avaliação possibilita ao coletivo diagnosticar problemas, refletir sobre eles e pensar em situações de melhoria ou superação.

Esse nível de avaliação se torna um instrumento valioso que uma instituição educacional pode construir e implementar "para produzir um conhecimento do desejável e do indesejável do interior da organização, [...] com o objetivo de subsidiar qualquer planejamento para melhorar a qualidade dessa organização" (MÜLLER, 2001, p. 7). Para o referido autor, a avaliação só poderá contribuir para a melhoria da qualidade "na medida em que a comunidade escolar for conhecedora dos dados revelados sobre a escola e pode refletir como anda sua prática que, pela sua decisão, vai ser mantida ou transformada" (MÜLLER, 2001, p. 12).

Conforme Tenório e Lopes (2010), a avaliação é uma atividade que comporta três grandes momentos: o primeiro é o de diagnóstico, quando se buscam informações fidedignas e precisas; o segundo é o de julgamento, quando as informações que foram coletadas, organizadas e analisadas servirão de base para a tomada de decisão com relação ao processo que está sendo avaliado; e o terceiro é o de uso da decisão visando à melhoria do processo. Sendo assim, toda avaliação "[...] somente faz sentido como parte de um processo de gestão que permitirá a ação posterior que visa à melhoria dos processos" (TENÓRIO; LOPES, 2010, p. 82).

Por isso, salientamos que a avaliação precisa ser incorporada como uma ação partícipe ao processo de gestão, para que seus diagnósticos possam resultar em planejamento e replanejamento das ações com menos traumas possíveis. Conforme enfatizam Tenório e Lopes (2010), a avaliação é um instrumento fundamental da gestão, pois se configura como um elemento de controle, de regulação e de negociação para a tomada de decisão.

Decidir é uma dimensão da gestão que também está implícita na avaliação. Em qualquer processo de gestão ou de avaliação, as decisões tomadas são ações que 
visam estimular e guiar os interessados [...] ao compromisso, à intervenção; e, visto que essas ações estão sujeitas ao planejamento e à avaliação, a tomada de decisão faz parte do processo de avaliação e gestão, aproximando-as e imbricando-as, o que permite compreender que a avaliação é uma forma de gestão. (TENÓRIO; LOPES, 2010, p. 72)

No entanto, vale ressaltar que a avaliação não é uma esfera que resolve problemas ou que inova. A avaliação é um instrumento utilizado para investigar a realidade e propiciar ao gestor a realização de intervenções. Segundo Luckesi (2012, p. 13), “[...] quem resolve problemas ou inova é o gestor, definido, aqui, num sentido bem amplo, como aquele que age, gerando os resultados que deseja e nos quais investe; isto é, aquele que decide e age”. Desse modo, a avaliação se apresenta com o "[...] papel de subsidiar o sujeito da ação em seus atos criativos e construtivos" (LUCKESI, 2012, p. 13). Além disso, é a avaliação que subsidia as decisões mais adequadas possíveis, já que, conforme Luckesi (2012, p. 18), “Sem o uso dos recursos da avaliação com rigor metodológico, as decisões seriam aleatórias e, por isso, arbitrárias". O gestor que procura verificar aquilo que está sendo feito, para melhorar ou reforçar, faz uso da avaliação que 1) subsidia a correção de um curso de ação, caso seja considerado inadequado ou
insatisfatório; 2) permite desistir de um curso de ação, caso se chegue à conclusão
de que ele não responde nem responderá ao que se espera; 3) permite inovar, ao
se descobrir que as qualidades obtidas não são as esperadas e desejadas; 4)
permite, por fim, concluir que se atingiu o que se desejava (o que se expressa
como "certificação" da qualidade dos resultados construídos, ou seja, como um
testemunho que, no caso, significa: "chegamos a um resultado satisfatório").
(LUCKESI, 2012, p. 20)

Reconhecendo que o desenvolvimento efetivo de uma gestão vai depender de outros campos, como financiamento, autonomia administrativa e pedagógica, descentralização e democratização, ainda assim acreditamos na importância de se fazer uso da avaliação nas instituições. A avaliação não é o fim último da gestão escolar, mas é uma aliada que fortalece a ação do gestor. Como argumentam Tenório e Souza (2010), na educação, medir, avaliar e informar são estratégias para o êxito da gestão escolar, já que, com os resultados, cabe à escola elaborar plano e medidas para melhorar os pontos fracos e fortalecer os pontos fortes diagnosticados.

Considerando que a avaliação é um processo permeado de informações relevantes que configuram um diagnóstico capaz de fornecer subsídios para a tomada de decisão, é tarefa primordial da gestão refletir como os usos das informações recebidas e produzidas podem estar a serviço da melhoria da gestão [...] e da qualidade social da educação, criando as condições propiciadoras para seu efetivo uso, juntamente com a equipe. (FERREIRA; DÉCIA; MASCARENHAS, 2010, p. 164) 
Considerando a complexidade de se garantir uma educação de qualidade pautada no direto à educação, na transmissão do saber produzido pela humanidade e na produção de conhecimento escolar, acreditamos que somente uma escola com qualidade seria capaz de realizar tal processo. Porém, o grande desafio, principalmente para a gestão escolar, se encontra em avaliar e definir a qualidade das instituições. Dessa forma, acreditamos que a gestão escolar pode lançar mão da avaliação institucional para diagnosticar a situação de sua escola e assim aferir sua qualidade. É nessa linha que se inscreve a possibilidade de fazer uma análise das pesquisas que vem sendo desenvolvidas nesse campo e saber se existe alguma ferramenta de avaliação que vem sendo utilizada e que pode auxiliar a escola nessa atividade.

\section{Tendências analíticas na BDTD}

Na composição do escrito, lançamos mão, como fonte de dados, da Biblioteca Digital Brasileira de Teses e Dissertações (BDTD). Para o mapeamento, utilizamos na pesquisa as palavras-chave "gestão escolar" e "avaliação institucional", em um primeiro momento, separadamente e, em um segundo momento, combinadas. Durante a pesquisa, encontramos 1842 estudos, sendo 1358 dissertações e 484 teses (Gráfico 1).

Gráfico 1 - Estudos encontrados com o uso das palavras-chave

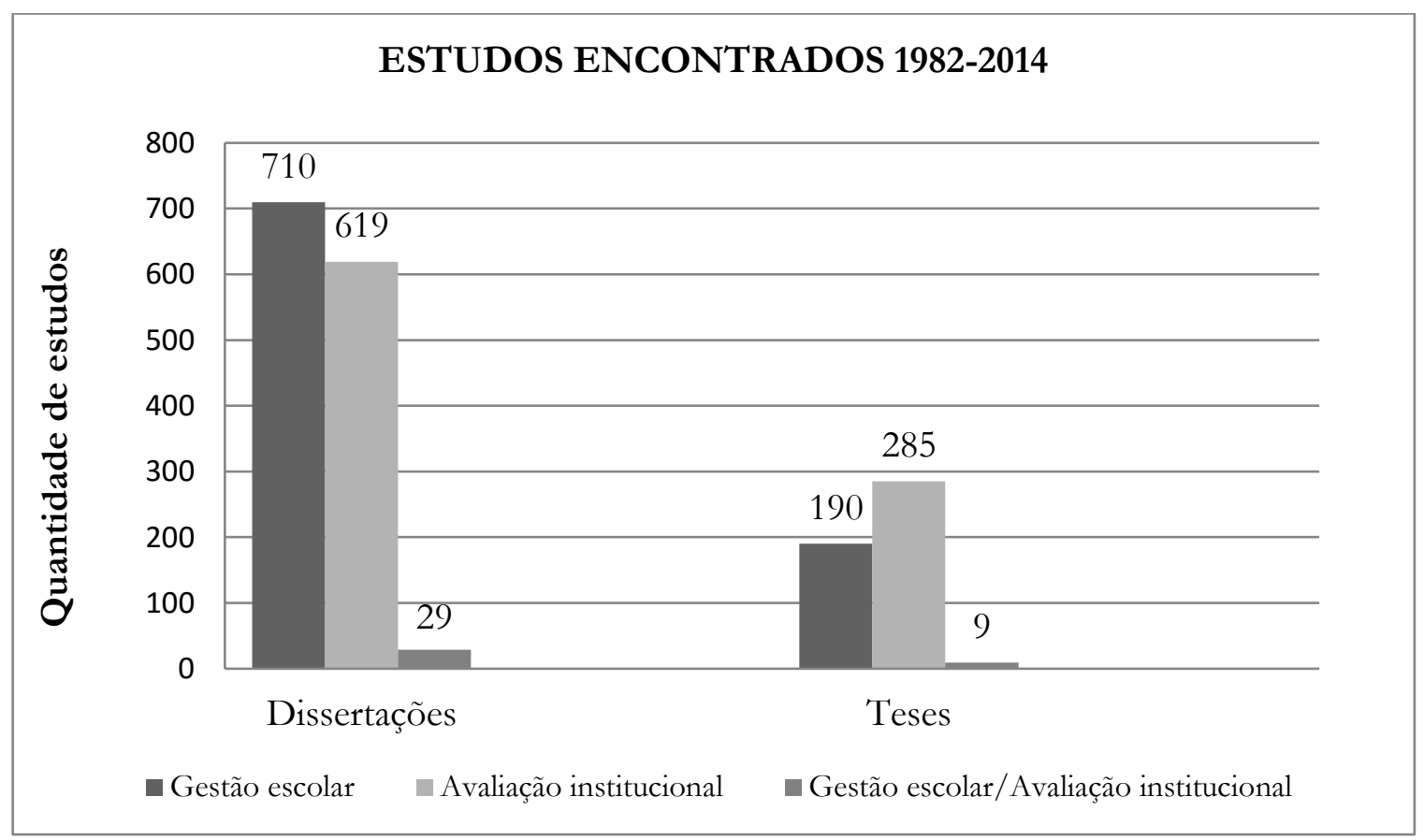

Fonte: Elaborado pela autora. 
Considerando o total de estudos encontrados que abordam as temáticas gestão escolar e avaliação institucional, para uma melhor condução da pesquisa, realizou-se um recorte temporal daqueles desenvolvidos nos (2010-2014), já que a pesquisa se deu durante o ano de 2015 e os artigos desse ano ainda não haviam sido inseridos na plataforma. Desse modo, o mapeamento reduziu-se a 1001 resultados, totalizando 783 dissertações e 218 teses (Gráfico 2).

Gráfico 2 - Mapeamento dos estudos nos anos (2010-2014)

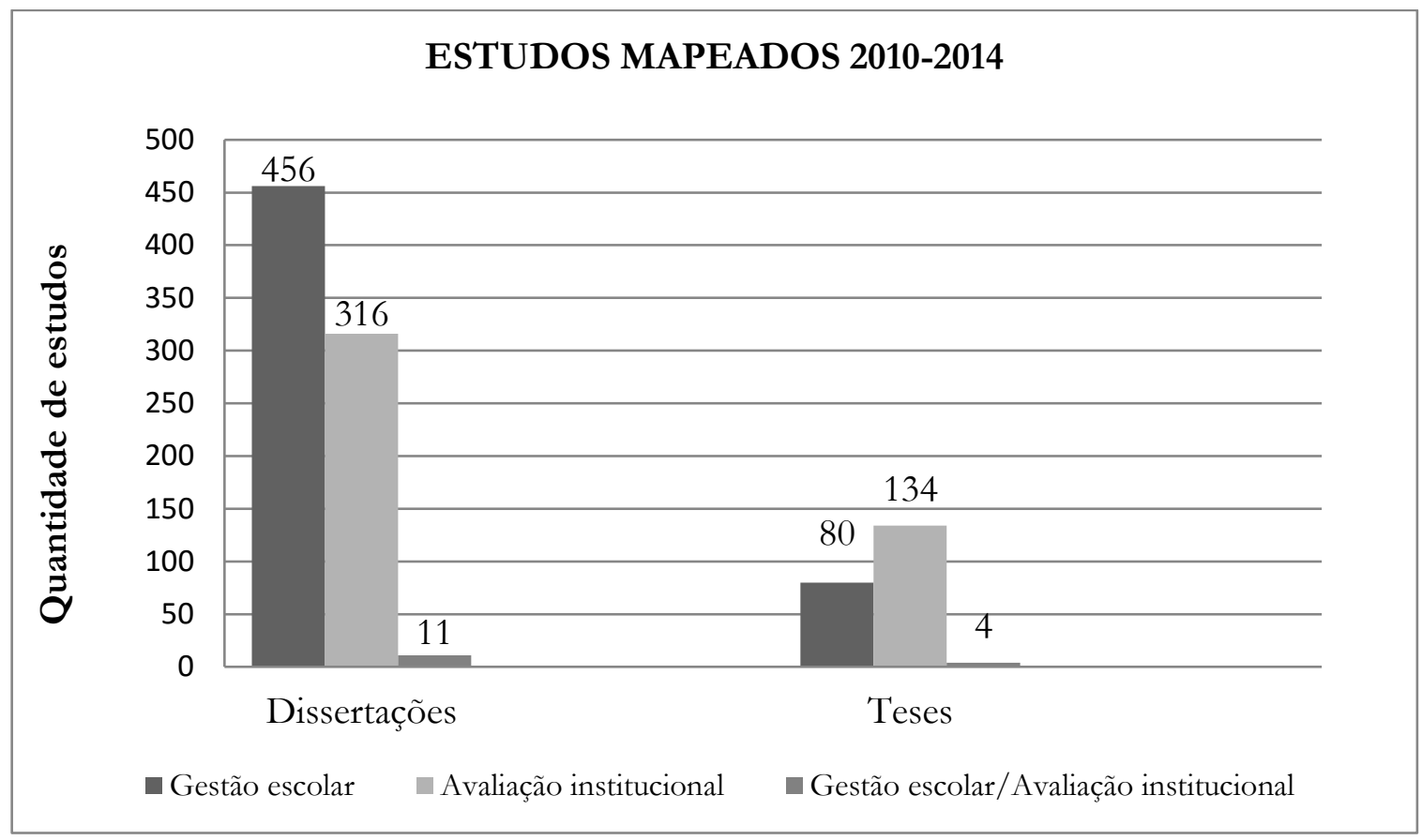

Fonte: Elaborado pela autora.

Dentro desse recorte temporal, foram selecionados 101 estudos para análise. Tais trabalhos demonstram as tendências analíticas predominantes das temáticas gestão escolar e avaliação institucional, obtendo o maior número em 2011 e o menor em 2014 (Gráfico 3). Dos estudos analisados, a maioria advém de programas de Pós-Graduação em Educação (88), e os demais de outras áreas como Administração (6); Ciências da Computação (1); Ciências (1); Psicologia (1); Comunicação Social (1); Engenharia de Produção (1); Políticas Sociais e Cidadania (1); e Gestão (1). 
Gráfico 3 - Estudos analisados de 2010 a 2014

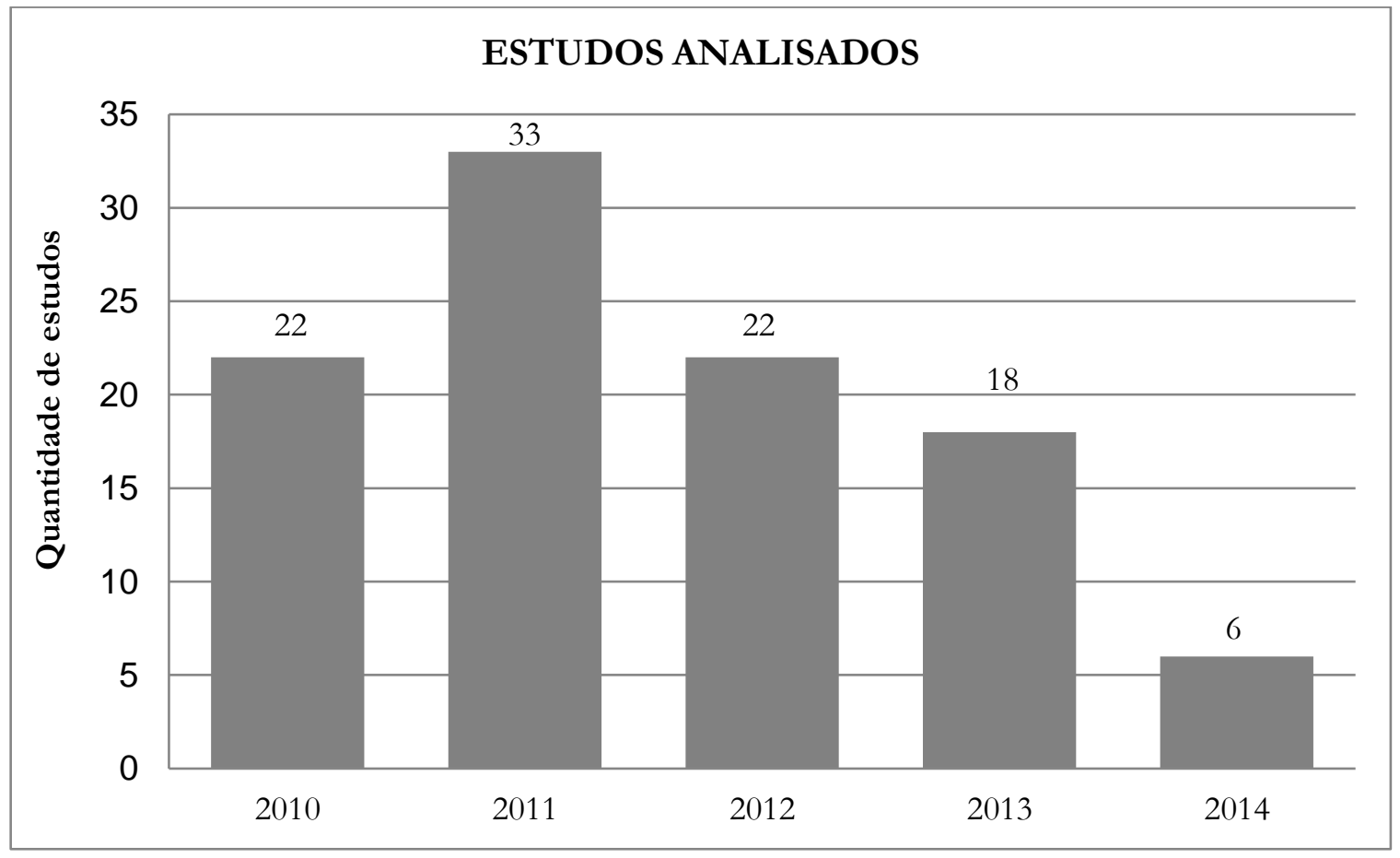

Fonte: Elaborado pela autora.

Os estudos mapeados se inscrevem em diversos enfoques: formação e perfil dos gestores; investigações acerca da implementação e da existência de gestão democrática nas escolas; gestão participativa; gestão compartilhada; eleição de diretores; atuação dos conselhos escolares; autonomia versus participação na gestão democrática; gerencialismo; gestão de qualidade; gestão articulada à avaliação; avaliação institucional na Educação Superior; avaliação institucional na Educação Profissional e Tecnológica; entre outras. Isso demonstra a existência de uma produção acadêmica com focos variados.

A análise dos estudos selecionados possibilitou classificá-los, então, em seis enfoques principais: formação, perfil e atuação do gestor escolar; implementação e existência de gestão democrática; modos de gestão democrática; gestão gerencialista; avaliação institucional na Educação Superior, Profissional e Tecnológica; articulação entre gestão, avaliação e qualidade (Gráfico 4). Os quatro primeiros enfoques se referem aos trabalhos que abordam a temática da gestão, encontrados a partir da palavra-chave "gestão escolar". O quinto enfoque se refere aos trabalhos cuja temática principal é a avaliação institucional, advindos da busca com a 
palavra-chave "avaliação institucional". Já o sexto enfoque é resultado da combinação dessas duas categorias.

Gráfico 4 - Enfoques analíticos dos estudos

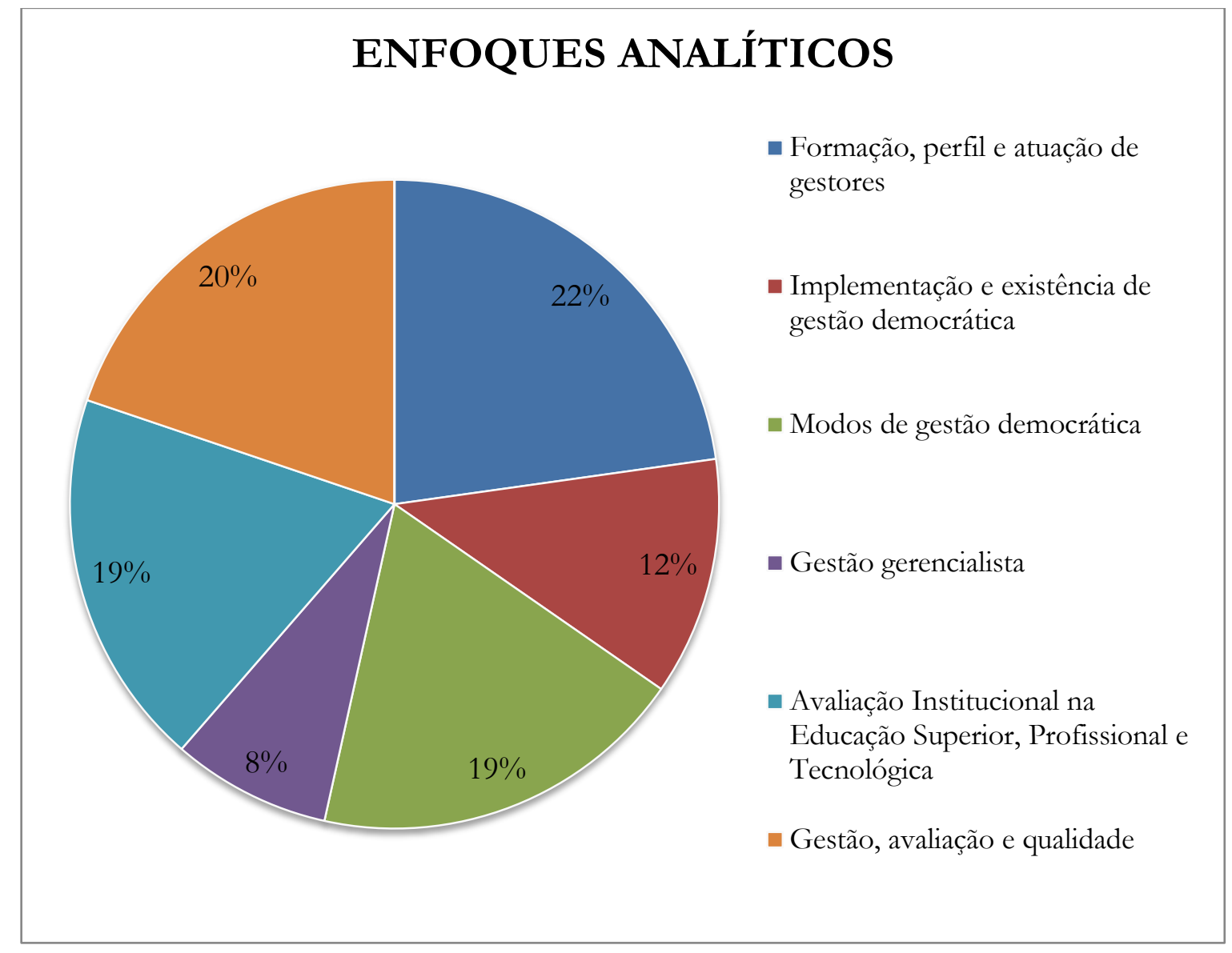

Fonte: Elaborado pela autora.

O primeiro enfoque analítico, que trata da formação, do perfil e da atuação dos gestores, perfazendo um total de 23 estudos. Destes, os que tratam da formação inicial e continuada do gestor escolar analisam os currículos dos cursos de Pedagogia formadores de gestores, os quais pregam a gestão democrática, mas, em seus conteúdos e vivências nas IES, parecem não coincidir com isso; avaliam cursos de formação como o Progestão (modalidade EAD), Parformação e Programa Escola de Gestores da Educação Básica, procurando saber como esses cursos têm contribuído para a prática dos gestores; e investigam como se dá a formação do gestor no cotidiano de seu próprio ambiente de trabalho.

Os estudos que abordam o perfil dos gestores buscam compreender o caráter dos diretores e da gestão das escolas; captar as representações de gestores sobre sua atuação; 
investigar as representações sociais dos diretores das escolas sobre gestão democrática; compreender qual identidade de gestor escolar é produzida dentro de uma lógica competente; além de compreender a construção social do conceito de "bom" gestor.

Já a prática do gestor escolar é pesquisada a partir da investigação de ações desenvolvidas pela gestão escolar, com vistas a construir uma escola inclusiva; da verificação da atuação dos gestores frente a programas como o PDE e o PDDE; da compreensão do fazer de um diretor eleito sem experiência na gestão escolar, alertando para a necessidade de políticas de formação; e do tratamento da intensificação do trabalho quanto a um envolvimento maior desses profissionais com a dimensão financeiro-administrativa de sua função em detrimento da dimensão político-pedagógica.

O segundo enfoque trata da implementação da gestão democrática em escolas e sua efetiva existência, compondo 12 trabalhos. As pesquisas objetivam analisar a implementação da gestão democrática em escolas municipais de João Pessoa; verificar o processo de implantação da gestão democrática nas escolas municipais de Alagoas e ações que transformaram o ensino nesse período; e investigar a trajetória de construção da gestão democrática da educação na rede municipal de ensino de Getúlio Vargas de 1993-2011, verificando se esta se opõe a um modelo gerencialista.

Já os trabalhos que focam a existência da gestão democrática buscam analisar práticas de gestão educacional em duas escolas públicas de ensino médio do DF, verificando se estas se efetivam como uma gestão democrática; investigar a existência de espaços de participação democrática nas escolas da rede pública municipal de Maceió, no período de 2005 a 2008; verificar as representações sociais dos gestores municipais de educação a respeito das mudanças ocorridas nas relações de poder dentro da instituição escolar após a municipalização; compreender as possibilidades e os limites da assunção de princípios democráticos na gestão escolar, tendo como cenário uma escola estadual situada no município de Duque de Caxias; investigar quais são as práticas democráticas vivenciadas no Sistema Municipal de Ensino de Tucano/BA, para compreender e interpretar o contexto a partir das visões dos sujeitos participantes do ato educativo; identificar como, no interior de uma unidade de educação básica, o discurso democrático é utilizado e quais são os procedimentos considerados característicos da gestão; pesquisar as escolas frente às reformas educacionais, tomando como referência a gestão democrática; investigar o que condiciona e o que potencializa a gestão democrática no cotidiano, na perspectiva da educação popular do campo; compreender a relação entre escola pública e democracia, mediada pela gestão 
democrática, na perspectiva dos gestores escolares, acreditando que o desenvolvimento democrático advém por meio de espaços de participação e decisão.

O terceiro enfoque analítico é composto por 19 trabalhos, os quais abordam os modos de gestão democrática, ou seja, a forma como a gestão democrática se materializa nas escolas. Os trabalhos que enfatizam a gestão participativa e a gestão compartilhada analisam a importância da gestão participativa para o desenvolvimento da escola pública em escolas de Belém, segundo a visão de seus gestores; evidenciam o processo de elaboração e os mecanismos de execução do PPP de uma escola, considerando-o um instrumento consistente na prática da gestão escolar democrática; investigam o programa gestão compartilhada como política pública de gestão escolar nos anos de 2008 a 2010 na rede de ensino do DF; visam constatar junto a uma escola da rede pública do DF ganhadora do Prêmio Nacional de Referência em Gestão Escolar se o modelo proposto nos livros referenciados se coaduna com o modelo de gestão compartilhada seguido por uma escola real; apresentam uma leitura das transformações promovidas pela regulamentação da gestão democrática do ensino público a partir da ideia de autonomia; investigam as possibilidades de participação das comunidades do campo na gestão escolar; buscam propor, com base na gestão democrática, contribuições ao modelo de um planejamento estratégico participativo em uma unidade escolar da rede estadual paulista.

Com foco na eleição de diretores, as pesquisas investigam se a implementação de eleição direta para diretor assegura uma gestão democrática na escola, tendo como critério de análise a participação e a autonomia no interior da escola; apresentam um estudo acerca da construção e da implantação do processo de eleição direta para a escolha de dirigentes de escolas públicas de educação básica da rede estadual de ensino do Rio Grande do Norte no período de 2003 a 2006; buscam identificar o quanto a escolha do diretor e a constituição do Conselho Escolar são importantes no fortalecimento da autonomia da instituição educativa, com foco na tomada de decisões pela coletividade; procuram compreender a maneira como a escolha do diretor da escola pública da educação básica pode influenciar na concepção e no desenvolvimento de uma gestão democrática e multidimensional; analisam a possibilidade de a gestão democrática funcionar como ferramenta de democratização e qualidade da educação, a partir do debate político e ideológico na tramitação da LDB de 1996.

Por fim, as pesquisas que trazem os conselhos escolares como forma de gestão democrática analisam a política que implantou os conselhos escolares em São Luís (MA); investigam a atuação do conselho escolar em duas escolas do DF; compreendem a atuação dos conselhos escolares como um importante local de discussão e explicitação de conflitos, 
enquanto órgão constituído pelo coletivo da comunidade escolar; procuram identificar quais são os principais fatores que interferem positiva ou negativamente na participação dos membros do conselho escolar nas escolas públicas do município de São Carlos (SP); discutem a participação dos professores na gestão da escola pública, no conselho escolar; r visam compreender a função, a composição e o funcionamento dos conselhos escolares.

Como quarto enfoque analítico, está a gestão gerencialista, abordada por oito pesquisas. Esse modelo de gestão se efetiva com moldes empresariais e neoliberais, afastando-se da gestão democrática. Desse modo, os trabalhos problematizam os desafios impostos à democratização da gestão do ensino público a partir dos novos marcos de referência para a gestão pública, tendo como objeto de estudo a proposta de modernização da gestão educacional no governo estadual do Rio Grande do Sul (Gestão 2007-2010) e evidenciando a inserção do modelo de gestão empresarial, de valores capitalistas de competitividade e premiação no âmbito escolar e do financiamento privado na educação; estudam as mudanças ocorridas na gestão educacional a partir das parcerias firmadas entre o município de Mossoró/RN e o Instituto Ayrton Senna para a oferta educacional, já que esse Instituto se insere na lógica neoliberal de modernização dos sistemas públicos de ensino, focalizando a eficiência, a eficácia e a maior produtividade; analisam a inexistência de uma gestão escolar democrática, posto que o que se efetua são modelos participacionistas conciliadores para a manutenção de um padrão autocrático de administração focado em moldes tayloristas e tecido em fios neoliberais (gerencialismo, individualismo, competitividade); investigam como se deu a implantação do PDE-Escola (proposta de planejamento estratégico a ser desenvolvida pelas escolas por meio de um modelo gerencial) na rede pública de João Pessoa/PB e sua contribuição na gestão dessas escolas; buscam descrever a ação gerencial de um diretor, destacando sua relação com os demais praticantes da comunidade escolar; analisam o planejamento e a gestão da escola pública no contexto da reestruturação produtiva e da reforma do Estado; visam compreender as implicações para a gestão escolar e para a organização do trabalho docente de parcerias público-privadas.

Por sua vez, o quinto enfoque se refere a um total de 19 pesquisas que abordam a avaliação institucional desenvolvida fora da educação básica. Os trabalhos cujo foco é a avaliação institucional da Educação Profissional e Tecnológica analisam a implementação da autoavaliação institucional no âmbito das IES que compõem a Rede Federal de Educação Tecnológica, os CEFETs, a partir dos pressupostos de autonomia, globalidade e participação preconizados pelo SINAES, no período de 2004 a 2009; investigam o papel da Avaliação Institucional na configuração do desenvolvimento do Instituto Federal de Santa Catarina; 
examinam resultados e melhorias no processo de meta-avaliação desenvolvido pelo grupo de trabalho do Sistema de Avaliação Institucional da Escola Técnica Estadual Parque da Juventude do Centro Paula Souza.

No que se refere à avaliação da educação superior, os trabalhos investigam como a Autoavaliação Institucional influencia o processo de tomada de decisão das Faculdades SENAC/SC; analisam se os resultados das avaliações institucionais em universidades contribuíram para a melhoria da gestão; verificam o processo de efetivação da Autoavaliação Institucional proposto pelo Sistema Nacional de Avaliação da Educação Superior (SINAES) para as instituições públicas e privadas; analisam alterações na atuação docente em sala de aula a partir dos resultados da Avaliação Institucional; se propõem a desvendar os aspectos da Avaliação Institucional, mais especificamente o processo de implementação da Comissão Própria de Avaliação, uma das dimensões criadas a partir da Lei n. ${ }^{\circ} 10.861$ pelo SINAES; discutem a avaliação institucional no contexto da privatização do ensino superior; analisam a relação entre a metodologia da Autoavaliação Institucional e a Gestão Pedagógica de Projetos em EAD; visam identificar o significado da Autoavaliação Institucional da perspectiva de técnicos-administrativos.

Por fim, o último enfoque analítico é resultante da busca de pesquisas que articulam as temáticas gestão escolar e avaliação escolar na educação básica. São pesquisas que, de alguma forma, buscam colaborar para melhorar a qualidade da educação via gestão e/ou avaliação escolar. Por isso, nomeamos esse eixo de gestão, avaliação e qualidade. Por se tratarem de estudos que vêm ao encontro do trabalho aqui desenvolvido, analisam-se as 20 pesquisas encontradas na seção que segue.

\section{Uso de ferramenta de avaliação institucional para a gestão escolar aferir a qualidade de uma instituição}

Como já explicitado, dos 101 trabalhos encontrados sobre gestão escolar e avaliação institucional, 20 articulam gestão, avaliação e qualidade em educação. Dessas produções, cinco são provenientes de doutorados, e quinze, de mestrados, distribuídas temporalmente entre os anos de 2011 e 2014 (Gráfico 5). A análise se deu a partir da leitura da íntegra dos trabalhos, com exceção de uma dissertação, à qual não se conseguiu acesso e foi feita a leitura de seu resumo. 
Gráfico 5 - Estudos de 2011 a 2014 analisados

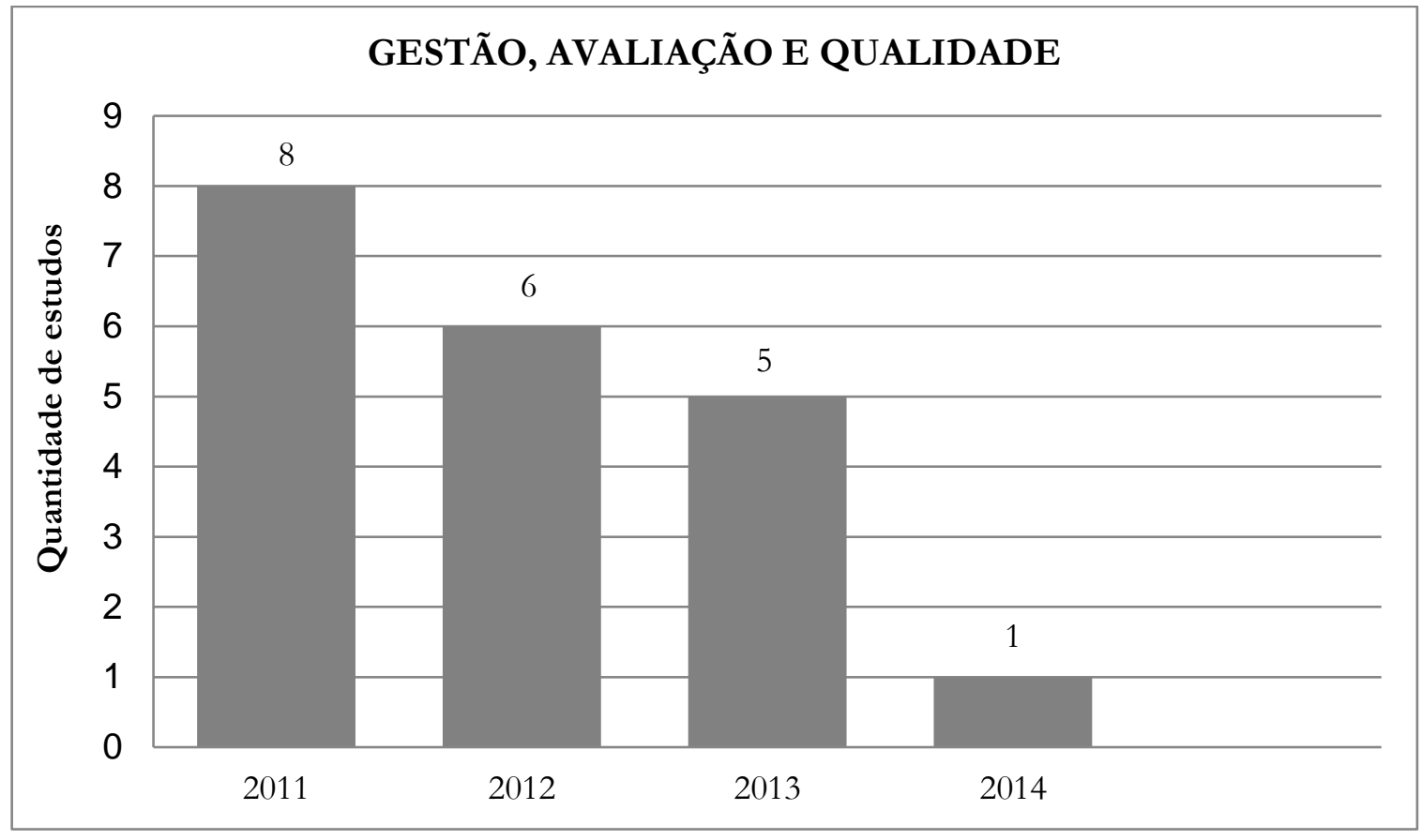

Fonte: Elaborado pela autora.

A análise dos trabalhos possibilitou dividi-los em quatro enfoques principais: modelos de gestão que visem à qualidade; influência da gestão sobre o desempenho dos alunos nas avaliações; uso da avaliação institucional para auxiliar a gestão; instrumentos/ferramentas para gestão/avaliação escolar.

O primeiro enfoque é composto por cinco trabalhos que discutem modelos de gestão para pensar a qualidade da educação. Um desses estudos teve como objetivo identificar os aspectos importantes sobre a formação de gestores da escola católica e aprofundar a análise sobre a possível relação entre a gestão e a qualidade da educação, de modo a ressaltar os valores inerentes à identidade e à missão da escola católica no Brasil. Nos resultados, constatou-se que a identidade confessional e a tradição da escola são os fatores integradores entre o modelo de gestão, o perfil do gestor e a qualidade da educação. Na pesquisa, concluiuse que o perfil do gestor com uma identidade confessional pode melhorar a qualidade da educação.

Outros dois trabalhos analisaram as consequências para a gestão escolar da utilização do Sistema de Gestão Integrado (SGI) em duas redes municipais de ensino fundamental. Conforme relatado nas pesquisas, o SGI é uma tecnologia de gestão idealizada pela Fundação Pitágoras e encontra suas raízes na Gestão de Qualidade Total, modelo de gestão que teve 
seu auge na educação brasileira na década de 1990. É um modelo de gestão privado que prioriza a melhoria dos processos administrativos na escola.

A qualidade da escola, para o SGI, está diretamente relacionada ao desempenho dos alunos e à ênfase nos resultados, sem propor condições para o avanço dos alunos na aprendizagem. À medida que for possível aumentar os índices de avaliação, a qualidade do ensino está garantida, e a função da educação escolar cumprida. É uma lógica gerencial com poucos preceitos democráticos. Esse modelo ajudou na sistematização do trabalho na escola; no entanto, essa sistematização parece estar ligada ao registro e à exposição dos dados, os quais valorizam o resultado, não o processo, além de proporem um excesso de atividades para os professores.

Dois trabalhos ainda tiveram como foco comparar modelos de gestão escolar brasileiros com modelos de outros países. Buscou-se descobrir qual modelo de gestão escolar de uma escola de qualidade ou se formas de gestões diferenciadas poderiam contribuir para melhorar a qualidade na educação. As pesquisas evidenciaram que o modelo de gestão escolar que levou as escolas pesquisadas a obterem bons resultados não é padronizado, ou seja, houve práticas administrativas e pedagógicas específicas. Assim, a qualidade dessas escolas não está diretamente relacionada a um modelo padrão de gestão escolar. Entretanto, apesar de existirem contradições, foram constatadas algumas similitudes no ato de gerir a instituição. Dessa forma, há a possibilidade de novos estudos para se conhecerem as melhores práticas utilizadas e se chegar a um modelo de gestão escolar que seja comum, para que as escolas obtenham maior qualidade.

O segundo enfoque, composto por três pesquisas, analisa a influência da gestão sobre o desempenho dos alunos nas avaliações. Os estudos buscaram comparar a gestão escolar de instituições públicas com resultados contrastantes em avaliações de larga escala para confirmar ou não que estratégias democráticas e fatores intraescolares relacionados à gestão favorecem o desempenho dos estudantes.

Constatou-se que escolas com melhor desempenho nas avaliações têm uma gestão mais democrática e organizada. Há indícios de que os mecanismos de gestão democrática podem auxiliar na superação de problemas apresentados no contexto de formulação de políticas educacionais por meio de avaliações em larga escala. Verificou-se também que os fatores internos das escolas desempenham papel importante e confirmam a relação existente entre gestão e desempenho. Desse modo, pode-se perceber que a gestão escolar hoje passa a ter um papel preponderante no compromisso por uma educação de qualidade, destinada a 
produzir transformações na gestão da aprendizagem. Assim, ela assume papel de copartícipe no desempenho dos estudantes.

O terceiro enfoque, presente em oito estudos, examina como o uso da avaliação institucional pode auxiliar a gestão escolar. Os trabalhos buscaram verificar como a escola pública da educação básica vem utilizando os resultados da avaliação institucional nas suas formas de avaliação interna e externa para o aprimoramento da gestão; analisar como uma escola estava antes e depois de constituir sua autoavaliação institucional; conhecer os limites e possibilidades do papel do Orientador Pedagógico como articulador do processo de implementação da Avaliação Institucional Participativa (AIP); investigar de que forma a avaliação institucional está presente no cotidiano escolar e como se dá a utilização dos dados por ela gerados na permanente construção do PPP das escolas; averiguar o processo de implementação de uma política de AIP em escolas do ensino fundamental; investigar a participação do colegiado escolar no processo de avaliação institucional; descrever as instâncias do sistema participativo da escola na perspectiva da AIP; e analisar formas de participação dos estudantes no processo de pactuação da qualidade da escola pública, favorecidas por políticas democráticas, como é a AIP.

De modo geral, os estudos sinalizaram desafios e possibilidades da avaliação institucional. Dos desafios, constatou-se que é ainda muito insignificante o papel ocupado pela avaliação institucional; existe uma cultura de avaliação classificatória que precisa ser repensada; há ainda resistência política e falta de participação de diversas instâncias (colegiado, alunos, pais). No entanto, também se demonstrou a importância de as escolas realizarem sua Avaliação Institucional Participativa, pois a avaliação institucional, quando efetivada de forma democrática, é um instrumento de monitoramento e aprimoramento da gestão da escola pública da educação básica. Ela possibilita à escola identificar seus pontos fortes e suas fragilidades; desse modo, pode ser usada como um instrumento para a superação das dificuldades em um processo que permite o aperfeiçoamento de práticas. Ficou evidente que o uso da avaliação institucional se torna indispensável para a gestão escolar pensar a qualidade da educação.

Por fim, o quarto enfoque é constituído de quatro trabalhos que apresentam instrumentos/ferramentas para a gestão/avaliação escolar: Sistema Integrado de Gestão Escolar (Siges); Web-pide; Programa de Qualidade da Educação (PQE); e Indicadores da Qualidade na Educação (INDIQUE). Como este é o eixo que mais se aproxima do objetivo que fixamos para a pesquisa proposta, apresentaremos os títulos e autores dos trabalhos. 
A dissertação Uso de sistema informacional na escola: um estudo das representações sociais de diretores de escola (SOARES, 2011) estudou a implementação do sistema informacional Sistema Integrado de Gestão Escolar (Siges). Esse sistema foi implantado na rede municipal de ensino de Santos - SP, possibilitando a informatização da rotina escolar. A programação do Siges combina dados cadastrados e gera relatórios com as mais diversas informações sobre a rede escolar, a escola, o curso, a turma e o aluno. Essas informações, acessíveis ao diretor de escola, podem auxiliá-lo na gestão escolar para a tomada de decisões. Com o estudo, evidenciou-se que o Siges é uma ferramenta administrativa que facilitou os trâmites burocráticos; no entanto, não foi reconhecido quanto à possibilidade de uso de seus dados para subsidiar a tomada de decisão no âmbito da gestão escolar. Isso indicou que o sistema informacional facilitou a rotina da escola, porém a cultura já estabelecida sobre gestão escolar permaneceu.

A dissertação Web-pide: uma plataforma de gestão escolar composta por serviços identificados a partir de diagramas de objetivos (SILVA, 2011) avaliou a plataforma Web-pide. Esta é uma Plataforma de Integração de Dados Educacionais proveniente de um projeto aceito pelo Observatório de Educação, criado pelo Instituto Nacional de Estudos e Pesquisas Educacionais Anísio Teixeira (Inep) e pela Coordenação de Aperfeiçoamento de Pessoal de Nível Superior (CAPES) para a submissão de projetos que auxiliem e facilitem o acesso de dados das avaliações de ensino. É uma plataforma que pretende tornar acessíveis os dados das avaliações do Inep.

O objetivo do trabalho foi desenvolver uma versão inicial dessa plataforma com atividades que auxiliem o gestor escolar a compreender os dados dessas avaliações e a melhorar a qualidade da educação, por meio de um planejamento estratégico. Desse modo, é o gestor que cria seu planejamento, o lança na plataforma e depois vai acompanhando o andamento das tarefas planejadas. Silva (2011) escolheu dar ênfase a atividades que auxiliassem o gestor porque, conforme pesquisas do autor, os gestores não possuem aplicações computacionais que os ajudem na gestão do ambiente escolar. A plataforma ainda é limitada, pois contempla apenas o módulo para o gestor escolar e auxilia no planejamento e no controle, além de não fazer integração com os sistemas administrativos das instituições de ensino.

A dissertação Avaliação Institucional: a qualidade nas escolas da diretoria de ensino da região leste 5 (MELO, 2013) investigou o Programa de Qualidade da Educação (PQE), implantado no Estado de São Paulo pensando na qualidade das escolas. Foi desenvolvido um instrumento de análise de qualidade institucional abrangendo cinco dimensões: 
infraestrutural, organizacional, gestão de pessoas, pedagógico e gestão de resultados educacionais. No total, 76 escolas responderam, com ajuda de toda a população, a esse instrumento-piloto de avaliação institucional. $\mathrm{O}$ autor observou certa falta de formalidade no instrumento, pois não existe um texto introdutório deixando claro quais são suas reais finalidades da aplicação, não se tem uma definição do que se espera ao fim da coleta dos dados e muito menos o que se espera mensurar nas unidades escolares. Esse instrumento não é um sistema informatizado, constituindo-se em um questionário impresso a ser respondido pela comunidade escolar.

Por fim, a dissertação $A$ qualidade do ensino na dimensão da gestão escolar democrática: um estudo de caso na EMEB Alfredo Naime a partir do INDIQUE (SALVET'TI, 2011) analisou os Indicadores da Qualidade na Educação (INDIQUE). Este é um instrumento de avaliação que visa ao envolvimento de toda a comunidade escolar em processos de melhoria da qualidade da educação. A pesquisa realizada teve por objetivo investigar a qualidade a partir do estudo de caso de uma escola que passou pelos processos de avaliação propostos por esse instrumento. $\mathrm{O}$ estudo concluiu que, apesar de restrições, a escola está no caminho de contemplar uma gestão democrática e que o INDIQUE se mostrou um rico instrumento de avaliação coletiva efetivamente democrático e contribuidor para a escola em diversas dimensões educacionais. $\mathrm{O}$ instrumento analisa sete dimensões: ambiente educativo; prática pedagógica e avaliação; ensino e aprendizagem da leitura e escrita; gestão escolar democrática; formação e condições de trabalho dos profissionais da escola; ambiente físico escolar; e acesso e permanência dos alunos na escola. É um instrumento que não enfatiza só o desempenho dos alunos, mas permite a discussão e a avaliação com a comunidade.

Temos, então, 20 pesquisas que articulam gestão e avaliação escolar para melhorar a qualidade da educação. A leitura das pesquisas que compõem os três primeiros enfoques nos possibilitou confirmar que a gestão escolar exerce influência sobre a aprendizagem dos estudantes e, consequentemente, sobre as avaliações a que estes são submetidos. Ao mesmo tempo, é indispensável que a gestão escolar faça uso da avaliação institucional para melhorar a qualidade educacional.

O último enfoque nos possibilitou conhecer alguns instrumentos/ferramentas que auxiliam a gestão escolar a realizar sua avaliação institucional. No entanto, apesar do Siges e do Web-pide serem instrumentos/ferramentas informatizados e terem facilitado alguns trâmites burocráticos, ainda possuem limites. Além disso, não há evidências quanto à possibilidade de uso de seus dados para subsidiar a tomada de decisão no âmbito da gestão escolar e auxiliar o planejamento estratégico. Já o PQE e o INDIQUE são 
instrumentos/ferramentas importantes para avaliar a qualidade das instituições; no entanto, seus dados são sistematizados apenas por questionários, limitando a divulgação e a avaliação dos dados, o que talvez pudesse ser melhorado caso houvesse um sistema informatizado.

Após a revisão desses estudos desenvolvidos nos anos de 2010 a 2014 sobre gestão escolar e avaliação institucional, confirmamos a importância do desenvolvimento de novas propostas de avaliação institucional que possam auxiliar o gestor escolar em suas tomadas de decisão, já que esse campo encontra-se ainda incipiente.

\section{Considerações finais}

Ao analisar-se teses e dissertações do banco de dados da BDTD dos anos de 20102014, pode-se constatar que a gestão escolar exerce influência sobre a aprendizagem dos estudantes e, consequentemente, sobre as avaliações a que estes são submetidos. Ao mesmo tempo, é indispensável à gestão escolar fazer uso da avaliação institucional para melhorar a qualidade educacional. No entanto, constatou-se a existência de poucas ferramentas/instrumentos que auxiliem a gestão escolar nessa avaliação institucional: Sige, Web-pide, PQE e INDIQUE. Apesar do Siges e do Web-pide serem informatizados e terem facilitado alguns trâmites burocráticos, ainda possuem limites e não há evidências quanto à possibilidade de uso de seus dados para subsidiar a tomada de decisão no âmbito da gestão escolar e auxiliar seu planejamento estratégico. Já o PQE e o INDIQUE, ao avaliarem a qualidade, consideram outras variáveis da instituição, para além da burocrática. Entretanto, seus dados não se constituem em ferramentas/instrumentos informatizados, o que dificulta o tratamento dos dados coletados. Portanto, ainda temos um longo caminho a percorrer nesse sentido, e a pesquisa aqui desenvolvida buscou contribuir para que futuros instrumentos/ferramentas sejam projetados e desenvolvidos nesse âmbito.

E em se tratando da avaliação institucional, os estudos sinalizam a Avaliação Institucional Participativa como um bom caminho para a gestão escolar diagnosticar e repensar sua instituição. Essa avaliação é que pode vir a aferir a qualidade social da escola pública que temos.

Por fim, salienta-se que temos o discernimento de que nenhuma ferramenta conseguirá apreender a realidade escolar (em sim mesma), deste modo, o uso dessa ferramenta é posto como uma forma de auxiliar a gestão escolar na busca pela qualidade social da instituição, e não como promotora dessa qualidade ou como capaz de definir uma qualidade " $\mathrm{x}$ " para uma instituição. 


\section{Referências}

BRASIL. Lei $\mathrm{n}^{\circ}$ 9.394, de 24 de dezembro de 1996. Estabelece as diretrizes e bases da educação nacional. Diário Oficial da União, Brasília, DF, 23 dez. 1996.

FERREIRA, Rosilda Aruda; DÉCIA, Ana Cristina M.; MASCARENHAS, Aília L. de J. Usos da informação para gestão educacional no município de Teodoro Sampaio. In: TENÓRIO, Robinson; MACHADO, Cristiane Brito; LOPES, Uaçaí de Magalhães (Orgs.). Indicadores da educação básica: avaliação para uma gestão sustentável. Salvador: EDUFBA, 2010. p. 157-172.

FREITAS, Luiz Carlos de et al. Avaliação Educacional: Caminhando pela contra mão. 3. ed. Rio de Janeiro: Vozes, 2011.

LIBÂNEO, José Carlos. Organização e gestão da escola: teoria e prática. 5 ed. revista e ampliada. Goiânia: MF Livros, 2008.

LUCKESI, Cipriano Carlos. Educação, Avaliação Qualitativa e Inovação - II. Brasília: Instituto Nacional de Estudos e Pesquisas Educacionais Anísio Teixeira, 2012. .

MELO, Diego Mubarack de. Avaliação Institucional: a qualidade nas escolas da diretoria de ensino da região leste 5. 2013. 154 f. Dissertação (Mestrado em Gestão e Práticas Educacionais) - Universidade Nove de Julho, São Paulo, 2013.

MÜLLER, Ademir. Avaliação institucional da gestão escolar na escola pública: a democracia no processo decisório. Santa Cruz do Sul: EDUNISC, 2001.

PARO, Vitor Henrique. Gestão escolar, democracia e qualidade de ensino. São Paulo: Ática, 2007.

SALVETTI, Thales André Silveira. A qualidade do ensino na dimensão da gestão escolar democrática: um estudo de caso na EMEB Alfredo Naime a partir do INDIQUE. 2011. $98 \mathrm{f}$. Dissertação (Mestrado em Administração de Organizações) - Universidade de São Paulo, Ribeirão Preto, 2011.

SILVA, Fernanda Aparecida Rocha da. Web-pide: uma plataforma de gestão escolar composta por serviços identificados a partir de diagramas de objetivos. 2011. 104 f. Dissertação (Mestrado em Ciências da Computação) - Ufscar, São Carlos, 2011.

SILVA, Maria Abádia da. Qualidade social da educação pública: algumas aproximações. Cad. Cedes, Campinas, v. 29, n. 78, p. 216-226, maio/ago. 2009.

SOARES, Elisabete Ferreira. Uso de sistema informacional na escola: um estudo das representações sociais de diretores de escola. 2011. Dissertação (Mestrado em Educação) Universidade Católica de Santos, Santos, 2011.

TENÓRIO, Robinson; LOPES, Uaçaí de Magalhães. Avaliação: implicações para a gestão escolar. In: TENÓRIO, Robinson; MACHADO, Cristiane Brito; LOPES, Uaçaí de Magalhães (Orgs.). Indicadores da educação básica: avaliação para uma gestão sustentável. Salvador: EDUFBA, 2010. p. 65-86. 
TENÓRIO, Robinson; SOUZA, Nayara. Prova Brasil: a avaliação a serviço da qualidade educacional. In: TENÓRIO, Robinson; MACHADO, Cristiane Brito; LOPES, Uaçaí de Magalhães (Orgs.). Indicadores da educaşão básica: avaliação para uma gestão sustentável. Salvador: EDUFBA, 2010. p. 263-273.

VIEIRA, Sofia Lerche. Política(s) e Gestão da Educação Básica:

revisitando conceitos simples. RBPAE, v. 23, n. 1, p. 53-69, jan./abr. 2007. 